\title{
COMPREHENSION DIFFICULTIES OF AUTHENTIC READING IN TEACHING ENGLISH AS A FOREIGN LANGUAGE (FLT) IN KAZAKHSTANI CONTEXT
}

\author{
Ainiya Abdrakhmanova ${ }^{1}$ and Dilraba Anayatova ${ }^{2}$ \\ Candidate of Pedagogical Sciences, Kazakh Ablaikhan University of International Relations and \\ World Languages, Foreign Language Teacher Training Faculty, Almaty, \\ Kazakhstan,ms.ainiya@mail.ru \\ Masters of Education, Kazakh Ablaikhan University of International Relations and World \\ Languages, Foreign Language Teacher Training Faculty, Almaty, Kazakhstan, \\ dilya.anayatova@gmail.com
}

\begin{abstract}
This article will concentrate on questions of methodology, namely comprehension difficulties of authentic texts. Over the past three years we had the benefit of continuing discussions with the staff and students of the Foreign Language Teacher Training Faculty at Almaty and most of what is worthwhile in this article derives directly or indirectly from them. This article is an attempt to explore certain difficulties in authentic reading that seems to us to arise from adopting a communicative approach to the teaching reading. It is the purpose of this article to reveal the reasons and causes that make reading hard and analyze the nature of errors. We must accept the commitment to propose a preparation and exploited exercises and the practical consequences of applying them as a teaching aim. The methods of the research include literature review, analysis of research cards, questioners, survey. In the study difficulties are classified into six groups according to their linguistic, semantic, syntactic, conceptual, extra linguistic features. They can be summarized as follows: a general lack of awareness about the principles of affixation, the use of expressions in a figurative sense, poor realization of metaphorical meanings of familiar words and phrases. The main aim of this article is to suggest basic rules and guidelines on avoiding errors in foreign language reading. The task before the teacher, then, is to help students change their reading habits by teaching them efficient reading strategies. An effective way to do this is through guided reading. For example, word-attack skills. These skills enable the reader to work out the meaning of unfamiliar words and phrases without looking them up in the dictionary. Here are two useful word attack skills: using context clues, and using structural information. Using context clues, includes using the meanings of other words such as synonyms and antonyms in the same sentence or paragraph, or the meaning of the sentence or paragraph as a whole, to deduce the possible meaning of unfamiliar words and phrases. Using structural information, this refers to word formation. An analysis of the stems and affixes of words can help our students get the meaning of many unfamiliar words. The meaning of the whole word can be worked out by analyzing its component parts. Reading in meaningful units, students should be able to read in meaningful units instead of isolated words. A useful way to train students to read in meaningful units is to break up a sentence into sense groups and have students focus their eyes on the middle of each sense group arranged in separate lines and try to see words on each side of the middle line. The transition of knowledge-based paradigm to competent based paradigm changed the aims and method of teaching reading. In competence-based approach which nowadays
\end{abstract}


presents an innovative process in FL Education and corresponds to the general conception of educational standards found in many countries. Comprehension of authentic reading suggests the presence of certain competences, as readiness and abilities to fulfill tasks. In this connection the meaning is not in the text, it is in the mind of the reader. Meaning is created depending on the background knowledge, experience of the reader and schemata. It goes without saying that reading comprehension largely depends on the technique of reading. However FL reading comprehension as a complex psycho -physiological process of cognitive activity should be regarded in the framework of Intercultural Communicative competence as the final goal of FLE outlined by many scholars (Canale and Swain, Savingon, S.S.Kunanbaeva) which involves different interpretations of the phenomenon and its structural components.

Keywords: strategy, conceptual, psycholinguistic, interaction, comprehension, authentic reading, affixation, glossary.

\section{INTRODUCTION}

"No surgeon would heal, no architect would build,

noscientist would research without all the teachers

that lead to those careers and many others".

Charles MrGuire

To begin this study we had to define what we meant by reading process since it is essential to have good theoretical backgroundand correlate the adequacy of reading skills with the research results. Let us approach this question by analyzing famous scientists' investigations within this field.First of all, Michael Swan's (2001)The Skill and Practice of Reading framework serves as a model. On account of the model under consideration, though reading is often considered a passive skill, research in the field of psycholinguistics has demonstrated that actually it is a highly complex process of interaction between reader and text. For example, it has been shown that the reader doesnot decode the text in his/her first language in an orderlylinear fashion, word after word, but rather that his/her eyes move rapidly over the page, going forward and backward as he/she perceives meaningful groups of words and relates these to the non-verbal information at his/her disposal (that is to his/her knowledge of the world and the topic of the written text), thereby deriving meaning from the text(Swan,2001,p.13).

Secondly, as Bj Thomas(2007) has pointed out, reading is one of those human capacities which tend to be taken for granted by those who do it effortlessly every day. Yet though it has been studied and scrutinized for generations by scholars from a variety of disciplines the process of reading remains a mystery since it's an activity which takes place in a part as the function of the brain as does language itself, questions about its nature are answered through constructing theoretical models of what might take place when the mind gets meaning from what the eyes see on the pages of print (Thomas, $(2007, p, 45)$.Moreover, with reference to language teaching, it will be readily agreed that we are now in the information age and this power belongs to those who have the knowledge and information.

This article will concentrate on questions of methodology, namely comprehension difficulties of authentic texts. Over the past three years we had the benefit of continuing discussions with the staff and students of the Foreign Language Teacher Training Faculty at Almaty and most of what is worthwhile in this article derives directly or indirectly from them. This article is an attempt to explore certain difficulties in authentic reading that seems to us to arise from adopting a communicative approach to the teaching reading. It is the purpose of this article to reveal the reasons and causes that make reading hard and analyze the nature of errors. The methods of the research include literature review, analysis of research cards, questionnaires,survey. In the study difficulties are classified into six groups according to their linguistic, semantic, syntactic, conceptual, extra linguistic features. They can be summarized as following:

- a general lack of awareness about the principles of affixation;

- the use of expressions in a figurative sense;

- poor realization of metaphorical meanings of familiar words and phrases; 
- understanding and using of phrasal verbs;

- choosing wrong prepositions;

- socio cultural terms.

The main aim of this article is to suggest basic rules and guidelines onavoiding errors in foreign language reading.

\section{DIFFERENT APPROACHES TO TEACHING READING}

As regards reading comprehension what exactly is 'reading comprehension'? If we say that a student is 'good at comprehension', we mean that he can read accurately and efficiently, so as to get the maximum information from a text with the minimum of misunderstanding.

Language is not the only factor in successful comprehension: some students who speak and write English very well are poor at this kind of work, and of course people may be bad at comprehension even in their own mother tongue.Some of the reasons for failure in comprehension are connected with defective reading habits. Not all students read efficiently, even in their own language, and there are several things that can go wrong:

a) Some students find it difficult to 'see the wood for the trees'. They may read slowly and carefully, paying a lot of attention to individual points, but without succeeding in getting a clear idea of the overall meaning of a text.

b) Other students (especially those who read quickly) do not always pay enough attention to detail. They may have a good idea of the general meaning of the text, but misunderstand particular points. Sometimes, by overlooking an important small word (for instance a conjunction, a negation, a modal verb) they may get a completely false impression of the meaning of part of the passage.

c) Some students are 'imaginative readers': especially if they know something about the subject, or have strong opinions about it, they may interpret the text in the light of their own experience and viewpoints, so that they find it difficult to separate what the writer says from what they feel themselves.

Other types of comprehension problem arise directly from the text. Even when a student is familiar with all the words and structures in a passage, complexities in the way the writer expresses himself may present obstacles to efficient comprehension.

d) Long and complicated sentences are difficult to cope with in a foreign language; even when the words are easy, syntactic complexity may cause a reader to lose the thread.

e) Some writers favorof a wordy and repetitive style; practice is needed to be able to 'see through' the words to the (often very simple) ideas which underlie them.

f) A writer may express an important idea indirectly. In order to understand some texts, one needs to be sensitive to the implications of a remark: to draw the necessary inferences from what is not stated directly. This is, of course, particularly difficult in a foreign language.

g) Words and expressions which the student does not know obviously present a problem.

As the diagnostic teacher works with a student, the teacher may ask herself, "What is inhibiting constructing meaning with the text? Is the student having difficulty recognizing the words (print processing), or understanding the content (meaning processing), or both?"(Walker, 2000, p,85).

Bain Ken (2004) has rightly stressed the significance of the question. In the learning literature and in the thinking of the best teachers, questions play an essential role in the process of learning and modifying mental models. Questions help us construct knowledge. They point to holes in our memory structures and are critical for indexing the information that we attain when we develop an answer for that inquiry. Some cognitive scientists think that questions are so important that we cannot learn until the right one has been asked: if memory does not ask the question, it will not know where to index the answer. The more questions we ask, the more ways we can index a thought in memory. Better indexing produces greater flexibility, easier recall, and richer understanding (Ken, 2004,p.112). The Kazakh Ablai Khan University of International Relations and World Languages has, in its official statutes on modern foreign language (MFL education, established various models to rank proficiency levels and structure various aspects of MFL subject content. It has structured subject content according to proficiency level in two forms of communication (spoken, written); modeled the integrated interaction of the components of the cognito-linguoculturological complexes(CLC) created an international, comparative model of proficiency levels for language and foreign language 
education. Key principle of subject- and progression-related content, can be defined as:

-'Thematic-textual unity/units (TTU) - D.N.Kulibaeva

•Communicative-functional block' (CFB) - A.B.Tynyshtykbaeva

-'Thematic complex' (TC) - N.K. Stamgalieva

•'Situational-thematic block' (STB) - G.D> Zakirova

The transition of knowledge-based approach to competence-based approach which represents nowadays an innovative process in FL Education, corresponds to the general conception of educational standards found in the majority of countries in the world and is directly connected with the transition from knowledge-based system to competence based system of constructing the educational process and the system of control for achieving of the new quality of education. In this connection reading comprehension as a complex psychophysiological process is first of all regarded in the framework of ICC (Intercultural Communicative Competence) outlined by many scholars (Canale and Swain, Savingon, J.Van Ek, L.Bachman, D.N.Kulibaeva, S.S.Kunanbayeva and others). For all the differences concerning the components of the ICC, they all demonstrate that the different approaches reflect that the ICC in a cognitive-based dynamic process of forming and developing a future inter mediator of intercultural communication. That is why we present Reading Comprehension in the frame-work of the model of the ICC suggested by S.S.Kunanbayeva in the following way:

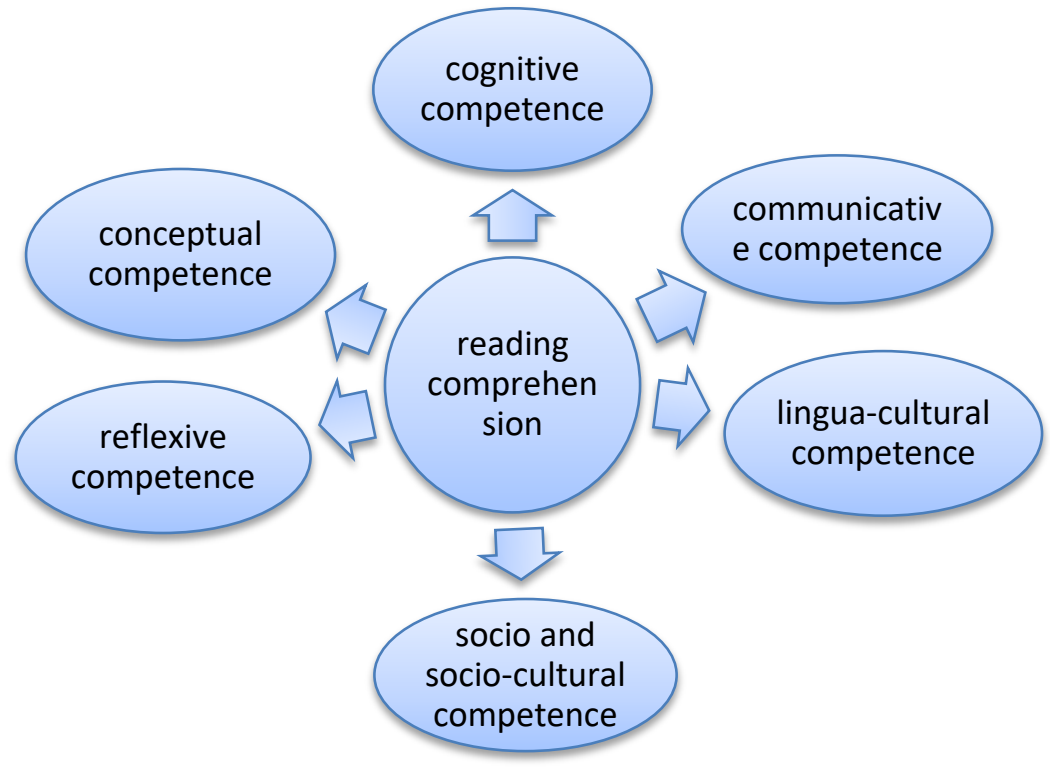

Fig. 1. Reading Comprehension in the frame-work of the model of the Intercultural Communicative Competence

1. Lingua-cultural competence in reading suggests lingua-cultural reflection of national language consciousness.

2. Socio and socio-cultural competence suggests secondary cognitive consciousness based on the native culture and language.

3. Conceptual competence provides the conceptual picture of the world.

4. Cognitive competence in reading is provided by cognitive mental structures of knowledge forming secondary conceptualization of the world.

5. Reflexive competence suggests the ability of the reader to analyze and evaluate the perception of information on the basis of cognitive structures.

6. Communicative competence in reading suggests the process of exchanging information between the author and the reader via the text.

We do not regard strategic competence and discourse competence separately. They are included into Communicative competence. 


\subsection{Teaching Reading Strategies}

Based on the psycholinguistic models of Goodman and Smith, Coady has developed a model of efficient reading. Efficient reading depends on the successful interaction among three factors higher-level conceptual abilities background knowledge and the process strategies which diagrams as follows:

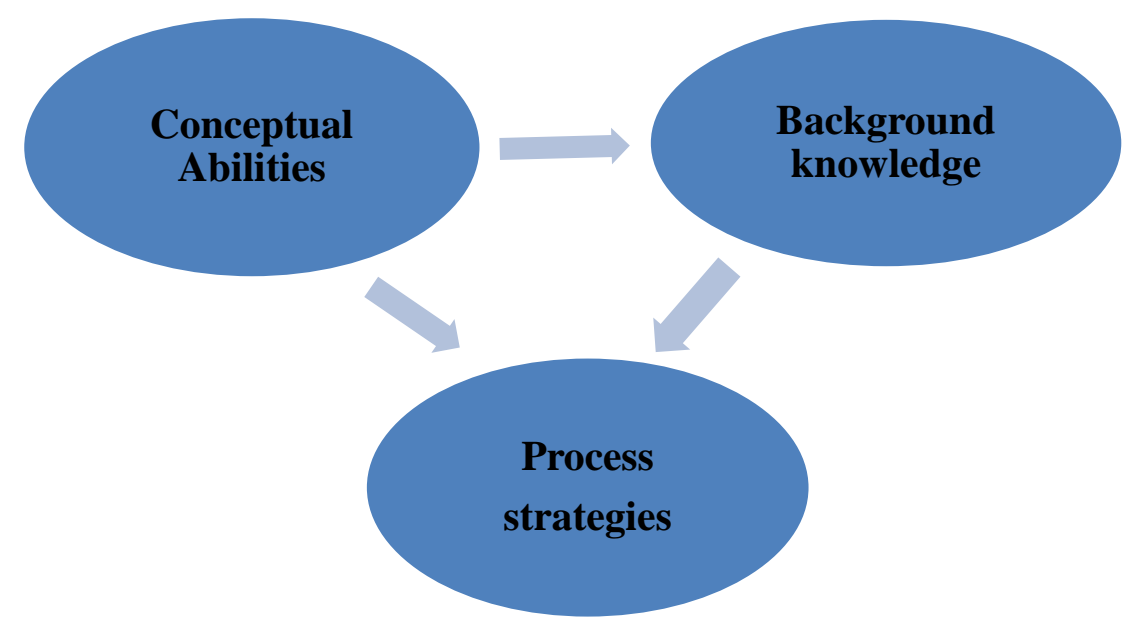

Fig. 2. The psycholinguistic model represents the significance of the three factors of efficient reading.

Conceptual abilities refer to intellectual capacity such as the ability to analyze, synthesize and infer. Background knowledge includes in particular sociocultural knowledge of the English-speaking communities. Process strategies refer to the abilities and skills to reconstruct the meaning of the text through sampling based on the knowledge of grapheme-morphophoneme correspondences, syllable-morpheme information syntactic information lexical meaning contextual meaning and cognitive strategies. Thus the ability to shift from more concrete to more abstract strategies indicates maturation in reading. Coady's model shows that it is possible for students to become efficient readers by bringing the three factors into successful interaction through appropriate training (Kral,1993, p.211).

To compare scholars' views we believe Widdowson's (2007) perspective need reviewing. He intends to concentrate on the relationship between reading and comprehending to bear on the practical concerns of language teaching. One of the difficulties we struggled with how can we present reading material in such a way as to persuade the learner to consider it as normal language use, even when it is not. To present someone with a set of extracts and to require the leaner to read them not in order to learn something interesting and relevant about the world but in order to learn something about the language being used is to misrepresent normal language use to some degree. The extracts are, by definition, genuine instances of language use, but if the learner is required to deal with them in a way which does not correspond to his normal communicative activities, then they cannot be said to be authentic instances of use. Genuineness is a characteristic of the passage itself and is an absolute quality. Authenticity is a characteristic of the relationship between the passage and the reader and it has to do with appropriate response.One solution is to provide a list of words and phrases and their meanings for the learners to go through before they begin to read. The words and phrases in a glossary of this kind are those which are judged to be outside the learner's current competence and which would otherwise, therefore, pose a comprehending problem.

We must clearly take care that passages do not present difficulties of usage which would prevent the learner comprehending to the extent necessary to read the passage effectively. Clearly a genuine instance of use cannot be authenticated if it consists of syntactic structures and lexical items which the learner just has not the competence to comprehend (Widdowson, 2007, p. 87).'An obvious example from the process of reading when they come across the phrase ....Perhaps 'they've turned over a new leaf" I thought as they greeted $m e$. The dictionary provides the following definition of the phrase: turned over a new leaf' - to change your life by starting to be a better person or stopping a bad habit. Often students can indeed infer from the context what a phrase means, and that is in fact the way in which we usually acquire both new words and new meanings for familiar words, particularly in our own first language. But sometimes students need to ask, and this is particularly true in the case of a second or foreign language. When students had difficulty in reading process the best professors looked for problems in our courses we asked ourselves how they could overcome difficulties with both motivation and comprehension. We carefully identified solvable problems with students' learning and constructed systematic ways for students to overcome those problems. But input from 
teachers is likely to be needed. The task before the teacher, then, is to help students change their reading habits by teaching them efficient reading strategies. An effective way to do this is through guided reading. Perhaps I should make it clear at this point that it is teacher's responsibility to facilitate tasks by means of utilizing different techniques andstrategies when they encounter with unfamiliar words. We followed up Michael Hoey's (2007) suggestion where he correctly identifies some strategies as follows:

- Using synonymous expressions

- Giving a general description and then narrowing it down with more specific features

- Drawing on encyclopedic knowledge (to suggest the contexts the word might appear in, to relate the word that is describing to other words, and so on).

Kral (1993) suggests for example, word-attack strategies. These strategies enable the reader to work out the meaning of unfamiliar words and phrases without looking them up in the dictionary. Here are two useful word-attack skills: using context clues and using structural information. This includes using the meanings of other words such as synonyms and antonyms in the same sentence or paragraph, or the meaning of the sentence or paragraph as a whole, to deduce the possible meaning of unfamiliar words and phrases. Strategy instruction has been discussed in general (see, e.g., Chamot\& O’Malles,1994). Using structural information, this refers to word formation. An analysis of the stems and affixes of words can help our students get the meaning of many unfamiliar words. The meaning of the whole word can be worked out by analyzing its component parts. We generally agree with this but also see the possible benefit of what theorists have proposed that there is the word-formation rule whereby many words are formed by adding affixes (prefixes and suffixes) to existing words. Likewise, affixation - affix a new part added to the beginning or end of a word that changes its meaning - prefix, suffix. If you know the meaning of the original word and the affix, you can often guess the meaning of the new word. What we need is some way of bringing out an official rule that says:Idiom - an expression whose meaning is different from the meaning of the individual words for example 'to have your feet on the ground' is an idiom meaning 'to be sensible'.For example, in the sentence "Exams are part of a carrot and stick method", there are obviously no real carrots and sticks involved. The image is that of a donkey being encouraged to move forward by dangling a carrot in front of it or by hitting it with a stick. We can use this idiom to describe any event that involves more abstract rewards (the carrot) and threats (the stick). As to: Figurative - using words not in their normal literal meaning but in a way that makes a description more interesting or impressive. I laughed until I nearly died, figuratively speaking of course.

\section{SAMPLE OF EXERCISES FOR READING PRACTICE}

We must accept the commitment to propose a preparation and exploited exercises and the practical consequences of applying them as a teaching aim. Which may be exploited during the reading classes

It is reasonable to admit Abraham Funchess's (2001), citation of an old Chinese proverb that says, "I see and I forget, I hear and I remember, I do and I understand". This approach follows the basic philosophy that science is a process in which students are active participants. Besides, exercises enable students to practice their skills and at the same time expose them to some linguistic units. Otherwise without the right kind of preexisting knowledge, comprehension becomes much more difficult.To illustrate preparation exercises, let us consider the following samples:

Exercise 1.Negative prefixes. Use the correct prefix (dis-, im-, mis-, un-) to make negative forms of the following words from the given:

1. appear: -

2. just: -

3. personal: -

Exercise 2. Which sentence illustrates the same use of the word (or idiomatic or figurative expression) as in the reading selection?

There are bound to be regional differences

a) the book is bound in leather

b) Children are bound to have some accidents as they grow up

c) The prisoner's hands were bound

Exercise 3.Take a close look at words in italics in these sentences, answer the questions that follow in 
writing:

1. One of the office personnel has a personal problem he wants to talk to you about.Which of the two words means the people employed somewhere? (personnel)

2. Let's proceedwith our business. Please precedeme in the conference room. Which word means to go on? (to proceed)Which means to go before? (to precede)

3. His affectionfor you were very real. His pretended respect for your father, however, was merely anaffectation. (an affectation)

Which word means a pretence?

4. Choose the word that most logically completes it.

There was no hope of - hours were spent in useless talk

a)conversation b) agreement c) satisfaction d) joy.

Exercise 4.In each line there is a "test word" followed by 4 possible meanings. Underline the word whose meaning is closest to that of the "test word".

Example: shut watch-close - pull - shine.

1. Labour harbour - strength - work - favour

2. Lad girl - teenager - boy - adult.

3. Liberty freedom - policy - library - effort.

4. aidvalue - race - advertisement - help.

5. Sufficient possible - understandable - enough - fine. Key: 1. work. 2.boy. 3. freedom. 4.help. 5. enough.

Following exercises deal with the exploitation of the vocabulary.

Exercise 1.Guessing unknown words.

As you will not be allowed to use a dictionary, you will have to do your best to guess the meaning. The main thing is to look at the context of each word- the sentence that it is in, and the sentences that come before and after. This will usually help you to get an idea of the meaning. (And look to see if the word repeated later in the text; the more often it is used, the easier it is to understand.) Unless your English is very good, you probably do not know the words 'dipstick' or 'stoat' As long as they are alone, there is no way of guessing what they mean, but see what happens when they are put into a context:

1. The car was making a funny noise, so I got out, opened the bonnet, and took out the dipstick to check the oil level.

\section{I heard a noise like a rabbit being killed by a stoat.}

It is not very difficult to guess that a dipstick is the metal rod that is used for measuring the oil level in a car engine, or that a stoat is probably some kind of aggressive animal (even if you cannot tell exactly what).Some words can be guessed from looking at their form. For instance, you may never have seen'unforeseeable' before, but the different parts of the word-un, fore, see, able- should each tell you something and help you to guess the meaning. What do you think 'discontinuous' and 'preselect' mean? What about 'inky black' and 'wavy hair'? Do not expect to be able to guess all the new words in a text. There will be some that you can only get a vague idea of, and others will be impossible. Do not waste time worrying about these: the most important thing is to understand the text as a whole as well as possible and one or two difficult words will not make much difference.

Exercise 2. You probably do not know many of these words: ungainly, boorish, knoll tacky, shamble, undercoat, glum, notch, and washer, gullible.

Look at the way they are used in the following sentences and then say, or write what you think they might mean. (Do not look in your dictionary, of course.)

1. She's a big ungainly girl - always braking things and falling over.

2. I've never met anybody as boorish as you are - what you said to me yesterday was absolutely unforgivable.

3. Napoleon rode up on to a little knoll to see the battle more clearly. 
4. Put the glue on the broken pieces, wait until it is tacky and then stick them together.

5. He must be tired: look at the way he's shambling along.

6. I can't get on with painting the bathroom until the undercoat's dry.

7. You're looking a bit glum - what's the matter?

8. California Pete had thirty-four notches on his gun: one for each sheriff he had killed.

9. I think we need a new washer. The tap keeps dripping.

10. She's amazingly gullible. I told her yesterday that Switzerland had declared war on China and she believed every word.

Keys:

Ungainly - not moving in an attractive or graceful way = awkward, clumsy

Boorish- rude and not caring about other people's feelings

Knoll - a low round hill

Tacky - slightly sticky

Shambling - to walk slowly in a tired or lazy way

Notch-1. A small cut on the edge or surface of something especially a cut shaped like the letter $\mathrm{V}$; 2 . if you move up or down a notch you move up or down to the next level.

Undercoat - the first layer of paint that you put on a surface

Gullible - a gullible person is easy to trick because they trust and believe people for easily = cynical

Glum - looking sad, as it you expect something bad to happen = gloomy

Exercise 3.Read the following short texts and answer the question that come after them.

The intention of other people concerned, such as the Minister of influence the government leaders to adapt their policy to fit in with the demands of the right wing, cannot be ignored.

What is the subjectof 'cannot be ignored'?

a) the intention

b) other people concerned

c) the Minister of Defence

d) the demands of the right wing

2. Theintention of other people concerned is

a) To influence the government leaders.

b) To adapt their policy.

c) To fit in with the wishes of the right wing.

d) That they should not be ignored.

Turning now to techniques of reading let us consider chunking. Chunking is a technique to encourage the student to read phrases of language that represent meaning rather than separate words. It focuses on reading phrases of text that represent a thought. Chunking facilitates comprehension and fluency by using thought units rather than word-by-word reading.

\section{Procedure}

1. The teacher chooses a passage at an instructional reading level that will take about three minutes to read.

2. The teacher tapes the student reading the passage.

3. The teacher and the student echo read (see "Echo Reading" in this chapter) the passage using meaningful phrases. In other words, the teacher reads a sentence modeling appropriate chunks of the sentence, and the student repeats the same sentence using the phrasing. The example that follows illustrates the sequence: 
Text: The bright girl liked to read stories about horses.

Student reading: The/bright/girl/liked/to/read/stories/about/horses.

Teacher modeling: The bright girl/ liked to read/ stories about horses.

Student echoing: The bright girl/ liked to/ read stories/about horses.

Teacher comment: I liked the way you chunked "read stories." Did it make more sense to you to read it that way?

1. The teacher and student continue reading the entire passage. When possible, the teacher increases the number of sentences chunked before the student repeats the model.

2. As the student's ability to chunk thought units increases, the teacher ceases to model the chunking, and the student reads the passage on her own.

3. The teacher tapes the reading of the passage again.

4. The teacher and the student compare fluency, intonation, and phrasing.

\section{CONCLUSION}

In conclusion having read and studied the works and research articles of the prominent scientists as Swan(1992), Kral(1993), Walker (2000), Thomas (2005), Halliday and Hasan (2001), on foreign language reading, it is reasonable to assume that all up-to-date approaches of teaching authentic reading one way or another are acceptable and effective. It will be generally acknowledged that the ultimate aim in language learning is to acquire communicative competence. Despite the fact that we are in advanced technology era reading stillremains so demanded. The approach mainly focuses on the analyses of the nature of errors or comprehension inhibitions and how they can be corrected. We attempted to cover the highlighted troublesome points indicated in the article. We also hope the issue presented here will be a topic of further research and valuable in teaching foreign language. Another thing is to shape some of the emerging conclusions as follows:

- The first thing for the teacher of FL reading to do is to find out the weaknesses or problems of her/his students;

- To provide students with a model of efficient reading by Goodman and Smith Coady (2006), i.e. bringing the three factors such as higher-level conceptual abilities, background knowledge and the process strategies into successful interaction through appropriate training;

- The input from teachers is likely to be needed. The task for the teacher, then, is to help students change their reading habits by teaching them efficient reading strategies;

- Guidance on how to tackle the tasks, to provide students with encyclopedic knowledge , official definition or description;

- Implement the examples of preparation exercises into the FL teaching process.

On the basis of a careful and informed examination of preparation exercises we can argue that we can no longer teach using one way because we have learned that students do not learn one way. Merely reach the correct answer has little significance if they do not understand the conceptual meaning. As teachers we need a bag full of tricks to reach and motivate our students. Many different approaching hands-on learning visual and auditory methods have to be utilized.

\section{REFERENCE LIST}

Charles MrGuire. The best Advice Ever for Teachers. 2001.

Kral T. (1993). Teacher Development, vol.245.

Davies, F. (1995).Introducing Reading. Penguin English, vol. 75. 
Flavell, M., Roger, H. (1985).Essential Language Teaching Series, vol. 180.

Haarman, L., Leech, P., Murray,J. (1990). Reading Skills for the social sciences,vol.33.

Hedge,T.(1985). Using Readers in Language Teaching. Essential Language Teaching Series, vol.235.

Ken, B. (2004). What the Best College Teachers Do, vol. 210.

Murray, J. (1988). Reading Skills for the social sciences, vol. 133.

Nuttal, Ch. (1982).Teaching Reading Skills, vol. 235.

Swan, M.(2001). Inside Meaning.Proficiency reading comprehension, vol.176.

Thomas, B. (2005). Advanced Vocabulary and Idiom, vol.322.

Walker, J. (2000). Diagnostic Teaching of reading, vol. 340.

Wallace,C. (1992). Reading. Oxford University Press, vol. 161.

Kunanbayeva S.S. (2013). The Modernization of Foreign Language Education: The LinguoculturalCommunicative Approach. United Kingdom, vol.293.

КунанбаеваС.С. (2010). Теория и практика современного иноязычного образования. Алматы, 342с.

Кулибаева Д.Н. (2002). Инновационная модель формирования международно-стандартных уровней владения иностранным языком в условиях школ международного типа. Алматы, 216с. 